\title{
Concentration system for volatile compounds detection
}

\author{
B. Rutecka ${ }^{1}$, J. Wojtas $^{1}$, J. Mikolajczyk $^{1}$, Z. Bielecki ${ }^{1}$ \\ \& T. Stacewicz ${ }^{2}$ \\ ${ }^{1}$ Institute of Optoelectronics, Military University of Technology, Poland \\ ${ }^{2}$ Institute of Experimental Physics, University of Warsaw, Poland
}

\begin{abstract}
Detection of trace amounts of substance is a challenging task in many technologies. Nowadays, a lot of detection systems operate at the detection limit. It is observed especially in such areas as medicine or security; for example, in explosive detection. In medicine, the technology of trace substance detection is associated with breath analysis. Some specific diseases can change the concentration of certain molecules (biomarkers) in the exhaled air. Because of the extremely low concentration of explosives' vapour and volatile compounds in exhausted breath, very sensitive detection instruments and an efficient system for their collection are needed. For this purpose, special devices - so-called concentrators - can be applied. Available solutions of the concentrators are dedicated to a specific detection system. The paper presents some projects of a concentration system, designed to cooperate with an optoelectronic sensor using cavity enhanced absorption spectroscopy (CEAS). Preliminary investigation showed that this setup provides the opportunity to detect $1 \mathrm{ng}$ of such explosives as TNT, PETN, RDX and HMX. The results have also shown that such instruments could be used to detect some disease biomarkers in human breath.

Keywords: optoelectronic sensor, explosives detection, breath analysis, concentrator system.
\end{abstract}

\section{Introduction}

The trace detection of volatile compounds is of great importance for various applications, especially in medicine and in public safety. The first of these areas is related to non-invasive method of health diagnosis like breath analysis [1]. In 
an exhaled air hundreds of volatile organic compounds (VOCs) like acetone, methanol or isoprene [2,3] and inorganic ones can be distinguished. Different concentration of some VOCs occurs in presence of various types of cancer (e.g. lung, breast) [4, 5], gastrointestinal, liver diseases [6] and diabetes [7]. However, inorganic volatile compounds can be also analysed as biomarkers of some diseases. For example, carbon oxysulfide (OCS) is a marker for lung transplant rejection and of liver disorders [8,9], carbon monoxide indicates oxidative stress, respiratory tract infection $[10,11]$, nitric oxide is connected with pulmonary disease [12] while ammonia in exhaled air provides the information about asthma, renal failure or $H$. pylori [13-16].

The second application of sensor systems is related to detection of trace amounts of explosive compounds. The traces of explosives could occur on e.g. suspect's hands or clothing. It is essential to prevent from terrorism acting and to increase security level of public transport and buildings. Most of explosive molecules are organic compounds. Carbon $(\mathrm{C})$, hydrogen $(\mathrm{H})$, oxygen $(\mathrm{O})$ and nitrogen $(\mathrm{N})$ are the main elements in their chemical structure. Furthermore, most explosives also contain nitro groups $\left(\mathrm{NO}_{2}\right)$. For this reason, they can be searched by $\mathrm{NO}_{\mathrm{x}}$ detection $[17,18]$.

Detection of trace amount of volatile compounds is a challenging task for any analytical system. The concentration of biomarkers in exhaled air are in the range of from several ppt (parts per trillion) to several hundreds of $p p b$ [19].The similar situation is with explosives vapours. Substances like trinitrotoluene (TNT), 2,4-dinitrotoluene (DNT), nitroglycerin (NG) or ethylene glycol dinitrate (EGDN) are characterized by relatively high vapour pressure. So they can be detected in ambient temperature. But some vapours pressure is so low that it is on the threshold or even below the detection limit of currently constructed sensors (e.g. pentaerythritol tetranitrate -PETN or hexogen -RDX) [20]. Therefore special concentrator devices can be applied. Fig. 1 illustrates an idea of concentration procedure. Firstly, target compound are trapped using a special sorption material (adsorbent). Then, this material is heated resulting in an increase in compound concentration or in its thermal decomposition products.

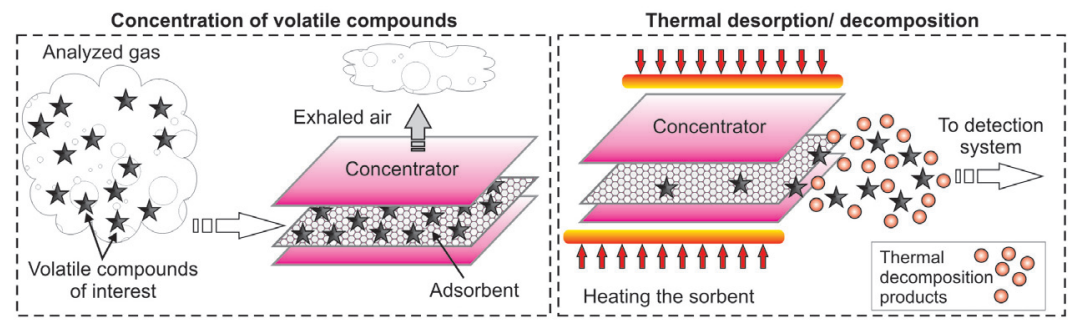

Figure 1: $\quad$ Idea of concentrating procedure of volatile compounds.

The concentrator device can be a very important sub-system that provides detection of very low gas concentration, even below detection limit of the sensor. 
That is why, in this article a review of concentrators' designs and materials used for adsorption of volatile compounds are presented.

\section{Concentrators design analyses}

The simplest construction of a concentrator consists of a glass or steel tube, inside of which is placed suitable sorbent material with a thickness of less than $1 \mathrm{~mm}$. In fig. 2(a) the cross-section through a concentrator structure is presented [21]. The heater is made from a thin layer of resistive material. A current flowing through this layer causes heating phenomena. A similar solution is shown in fig. 2(b). In this case, a metal tube is wrapped in nichrome wire, which is able to heat the tube.

a)

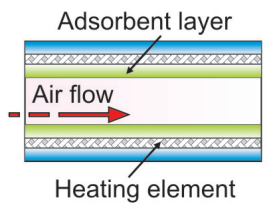

b)

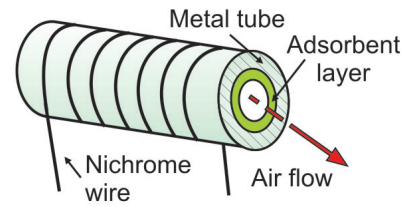

c)

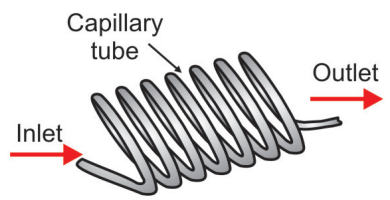

Figure 2: The cross-section of the concentrator structure (a), tube type concentrator heated construction (b), coiled tube design (c) [22].

In some cases, it is necessary to minimize length or volume of the concentrator. So, device may comprise a coiled capillary tube (fig. 2(c)). Such design has several advantages like reduction of heat losses due to decreasing in size packaging, exposure to environmental temperature, and in its fluctuations [23].

In the next example of a concentrator construction a membrane coated with an adsorbent material is applied (fig. 3). The construction is also equipped with a fan or a pump to provide a continuous air flow through the filter. Using this setup, a large volume of storage is obtained an increase in volatile compounds adsorption can be observed [22].

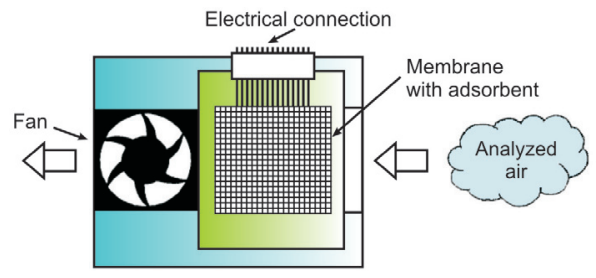

Figure 3: Concentrator with membrane coated with an adsorbent material.

Next type of concentration systems are based on micromachined (MEMS) technology. An example is a planar micro-concentrator made from a silicon. It was applied in detection of explosives in the $\mu$ ChemLab sensor. The cross 
section through this structure is shown in fig. 4(a). The heater is built of a platinum layer $(\mathrm{Pt})$, which is covered by a microporous adsorbent layer [24].

Another two systems basing on planar perforated plates are coated with a heating polymer [25]. The structure of the first one is produced using the perforated kapton (polyamide) membrane, which is suspended on a silicon frame. Matrix of rectangular holes in a membrane provides perpendicular flow of air through an adsorbing layer (fig. 4(b)). This concentrator was tested with a chemical light sensor - LCD 3.1 [26].

a)

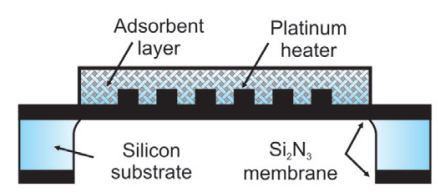

b)

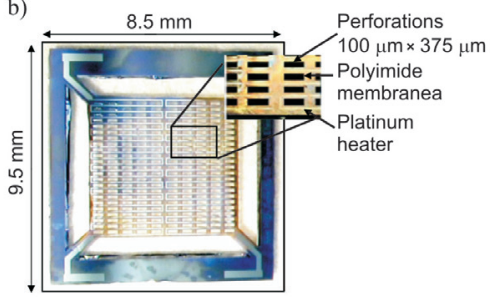

Figure 4: Cross section of a planar structure (a), planar concentrator with a heating polymer (b) [27].

In this device, a silicon substrate is covered by a performed heating layer made from silicon dioxide supplemented by a semiconductor oxide layer formed in CMOS technology. Concentrating system was tested with a Vapour Tracer II instrument [28].

The next devices consist of a spiral-shaped micro channel, housing a porous adsorbent powder. The heating pulses are formed using a platinum heater patterned on the Pyrex glass cover. The device is able to detect benzene in air with the level of $p p b$ [29]. The similar construction was applied in acetone concentration measurements [30].

As a concentrator device, a solid-phase microextraction (SPME) can be used. This technique applies a special syringe fitted with a silica fibre. The fibre is coated with a thin adsorption layer (fig. 5). SPME is effectively used with gas chromatography-mass spectrometry setup. The detecting procedure consists of two stages: during the first one, fibre has direct contact with a gas-phase sample (or liquid-phase). In this process, adsorption of analytes is noticed. In the second stage, the fibre is exposed to high temperatures in a hot-gas injector of chromatograph. Released analytes are transferred to the chromatographic column, where they are separated and quantification. SPME can be applied in both VOCs analysis of human breath e.g. in $H$. pylori [31] or cancer tissues detection [32, 33] and in molecules collection of explosives [34].

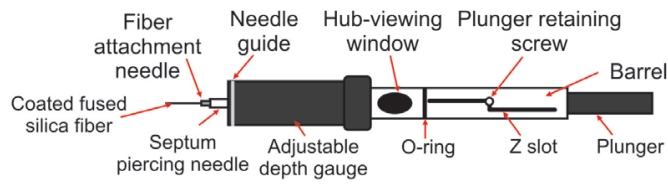

Figure 5: $\quad$ Scheme of SPME syringe. 


\section{Adsorbing materials}

Properly choice of adsorbing substance is an important factor in construction of any concentration device. Generally, adsorbent is a material which is capable of extracting certain substances from gases, liquids, or solids by adhering process without changing its physical properties [35]. This substance should have a high adsorption capacity, a strong affinity with the investigated gas, fast rates of adsorption and desorption action, as well as good stability and durability [36].

In the market, there are some materials that can be used for the adsorption of volatile compounds. In such applications, carbonaceous materials, zeolites and polymers are very effective [37].

The main carbonaceous adsorbent is an activated carbon (AC). It is made from organic materials such as wood, peat, fossil coals, oil or coconut shells and nuts. Activated carbons have a microcrystalline structure. This structure is consisted of six atomic carbon rings irregularly distributed on the network. These rings may be connected with various functional groups improving the efficiency of the adsorbing process. These materials were found to be promising tool in retention of aromatic VOCs [38, 39]. Basing on activated carbon, some types of commercial adsorbents have been developed. Typical ones include an activated charcoal, Carbotrap, and Carbosieve [40]. The application of carbon nanotubes and nanoporous carbons was also reported in adsorption of nitrobenzene [41]. A very attractive adsorbing material is Carbopack, It was used in detection of VOC's like benzene, toluene or xylene [29, 42] and explosive vapour [43].

The next group of adsorbents are zeolites. They are crystalline hydrated aluminosilicates that may also contain other metals, such as sodium, potassium, magnesium and calcium and that has ion exchange properties [44]. The zeolites are composed of tetrahedrons of $\left[\mathrm{SiO}^{4}\right]^{4-}$ and $\left[\mathrm{AlO}^{4}\right]^{5-}[45]$. In the natural environment there are ca. 40 different types of zeolites. However, there is also a much larger group of zeolites, which can be synthesized. Due to homogeneous pore size of synthesized zeolites the selective adsorption of different compounds is possible. Therefore, these materials are often be used as molecular sieves $[46,47]$. In such form, they can be applied in concentration measurement of exhaled gases. For example, zeolite can be used to adhere acetone [48]. Using these devices, it is possible to detect perfluorocarbon (PFC) which has been widely used in the treatment of respiratory diseases [49].

The last group of adsorbents form polymers, which are a produced synthetically. The most popular one is Tenax. It can be used for various analytical applications for example in detection of volatile compounds which are cancer biomarkers $[50,51]$. Tenax is also widely used in adsorption of both explosives vapour and explosive-related compound [37, 52]. Another commercially available polymer is a Carbowax. This polymer has strong hydrogen-bond acidic so it provides reversible sorption processes of a substance with nitroaromatics group (e.g. DNT) [53]. Similar properties have a different polymer known as polidimethyl siloxane (PDMS) [54]. 


\section{Examples of concentrator application}

The most of concentrator systems are dedicated to cooperation with specific sensors. In the frame of science projects carried out at the Institute of Optoelectronics MUT some constructions of optoelectronic sensors employing CEAS method were developed. They were designed to measure a trace concentration of nitrogen dioxide $\left(\mathrm{NO}_{2}\right)$, nitric oxide $(\mathrm{NO})$, and nitrous oxide $\left(\mathrm{N}_{2} \mathrm{O}\right)$. The main elements of the sensors were pulsed laser diode, optical cavity, photoreceiver, signal processing unit, and a computer with special software [55-58].

Investigations of a laboratory model of the $\mathrm{NO}_{2}$ sensor showed that it is characterized by a high selectivity and high sensitivity reached the level of $1 \mathrm{ppb}$. The mobile construction of the sensor is presented in fig. 6 [59].

Other developed sensors provide to detect $\mathrm{N}_{2} \mathrm{O}$ and $\mathrm{NO}$ with the detection limit of $50 \mathrm{ppb}$ and $70 \mathrm{ppb}$, respectively [60].

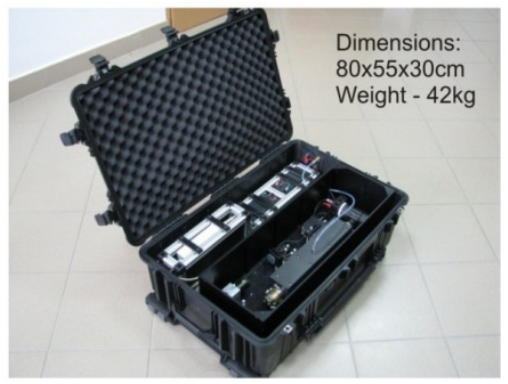

Figure 6: Photo of portable nitrogen dioxide sensor.

Our optoelectronic $\mathrm{NO}_{\mathrm{x}}$ sensors are able to detect some explosives. This is related to the fact that the most popular explosives are nitro compounds, which emit trace amounts of nitrogen oxides. Preliminary studies were performed using the portable sensor in one of Polish mine. During investigations, the explosive devices with NG and ammonium nitrate were searching. The experiments showed that the designed sensor makes it possible to detect people and objects having traces of explosives as well as to find explosive materials in non-hermetic package [61].

But the obtained results showed, that in the case of weak pressure of explosive vapour, the sensitivity of the sensor is too low. That is why, during another experiments, some concentrators of explosives vapour with different sorbent materials were applied. The concentrators were constructed at the Institute of Optoelectronics (MUT) and Institute of Experimental Physics (UW) [62-64]. The first construction provides to achieve a high air flow with level of about $38 \mathrm{~L} / \mathrm{s}$. The vapours of the explosives are collected with the adsorbing material in a special container made from gilded copper (fig. 7). Perforated quartz tube runs along the container axis. Due to that, the analysed air is flowing through the sorbent. The volume of the container construction is about 
$0.4 \mathrm{~L}$. To achieve a high gradient of the decomposition temperature (about $100^{\circ} \mathrm{C} / \mathrm{min}$ ) a quartz lamp heating was applied. The concentrator operation is monitored by a special controller.

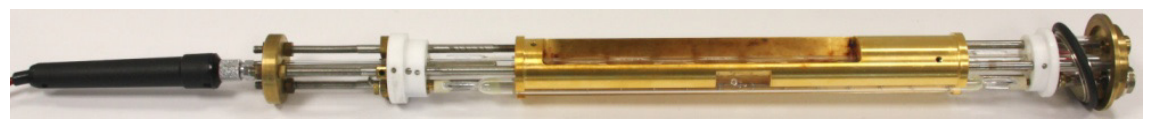

Figure 7: Photo of lamp heating concentrator.

In the second construction, an induction generator was applied (fig. 8). Due to that an extremely high temperature gradient of the sorptive material (about $1 \mathrm{~cm}^{3}$ ) was achieved (up to $1000^{\circ} \mathrm{C} / \mathrm{min}$ ). This device provides an air flow up to $5 \mathrm{~L} / \mathrm{min}$. The adsorption and decomposition processes are controlled by a microprocessor unit. Moreover, the concentrator construction is portable and can be supplied with two batteries (12V, 7Ah) [65].

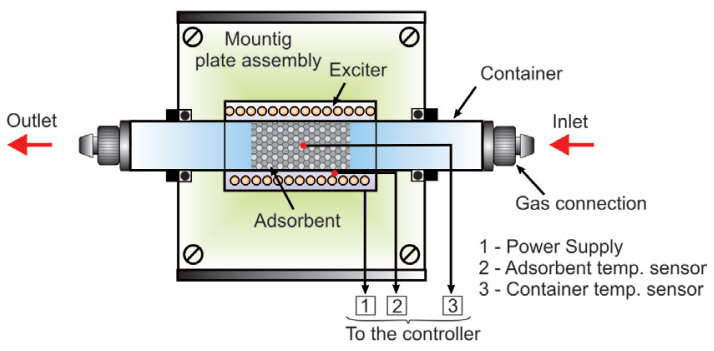

Figure 8: $\quad$ Scheme of induction concentrator.

Another construction of a concentrator was developed to collect $\mathrm{NO}_{\mathrm{x}}$ molecules directly from the explosives [64]. Its most important feature is a lowtemperature operating (up to $60^{\circ} \mathrm{C}$ ). The main elements of the concentrator are several Peltier modules (TEC) coated with a special sorption material. In this case, copper oxide was used (fig. 9).

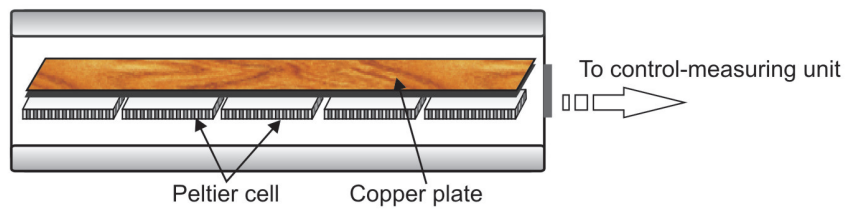

Figure 9: $\quad$ Scheme of $\mathrm{NO}_{\mathrm{x}}$ concentrating device.

TEC modules make it possible to adjust appropriate sorbent temperature. When samples of investigated air are injected into the device, nitrogen oxides are 
deposited on the sorption material. Next, desorption process is carried out. This process releases collected nitrogen oxides.

Nowadays, in the Department of Optoelectronics at the Silesian University of Technology, very intensive investigations have been also carried out dealing with the development of concentrative and sensing systems for the detection of explosive vapours $[62,63]$. The systems are constructed basing on nanotubes of $\mathrm{ZnO}, \mathrm{TiO}_{2}$ and polymer structures. Applications of the nanotubes in explosive vapours sensors allows to miniaturise their construction and to reduce essentially the productions costs.

\section{Conclusion}

Simpler, faster and more sensitive measurement of trace volatile compounds is very important for various applications. Furthermore, it is very significant to be able to detect a specific compound characterized by a low concentration. Through the use of a concentration system, parameters of the entire detection system can be significantly improved. Nowadays, a large group of commercial concentrators are dedicated to GC-MS sensors. The development of sensors basing on CEAS detection, preliminary research and the analyses of their applications in military (explosives detection) and in medicine (detection of diseases markers), led the authors to construct three concentrators of gas particles. The experimental results showed that these devices may be used in concentration or thermal decomposition of explosives vapours. Moreover, developed sensors and concentrators may be applied for routine air monitoring in industrial area, detection of explosives in airports, finally in medicine to breath analysis.

Summarizing, the developed $\mathrm{NO}_{\mathrm{x}}$ sensors and the concentrators with sorbent materials such as Tenax TA and Carboxen 1000 were used for TNT detection. This sensing setup makes it possible to detect some explosives (TNT, PETN, RDX and HMX) with concentration of $1 \mathrm{ng}$ [61].

During the next experiments the similar system will be developed to detect the markers of some diseases $\left(\mathrm{NO}, \mathrm{OCS}, \mathrm{NH}_{3}\right.$ ) existing in human breath. Application of CEAS method is recommended because of its high sensitivity and high selectivity. Our future works will be concentrated on development of an optoelectronic sensors system for determination of biomarkers in exhaled human air.

\section{Acknowledgements}

The presented works were supported by The National Science Centre, The National Centre for Research and Development in the scope of Projects: DEC2011/03/N/ST7/03401, No. OR00002807, No. OR00017912, ID: 179616, ID: 151673 and ID: 179900, and the European Union under the European Social Fund. 


\section{References}

[1] Miekish W. and Schubert J., From highly sophisticated analytical techniques to life-saving diagnostics: technical developments in breath analysis. Trends Anal. Chem., 25(7), pp. 665-73, 2006.

[2] Miekisch W., Schubert J. and Noeldge-Schomburg G.; Diagnostic potential of breath analysis-focus on volatile organic compounds. Clin. Chim. Acta, 347, pp. 25-39, 2004.

[3] Zolotov Yu A, Breath Analysis. J Anal Chem., 6(60), pp. 497, 2005.

[4] Bajtarevic A., Ager C., Pienz M., Klieber M., Schwarz K., Ligor M., Ligor T., Filipiak W., Denz H., Fiegl M., Hilbe W., Weiss W., Lukas P., Jamnig H., Hackl M., Haidenberger A., Buszewski B., Miekisch W., Schubert J. and Amann A., Noninvasive detection of lung cancer by analysis of exhaled breath. BMC Cancer, 9, pp. 348, 2009.

[5] US Patent US 2012/0326092 A1. Volatile organic compounds as diagnostic markers for various types of cancer. 2012.

[6] Probert C., Ahmed I., Khalid T., Johnson E., Smith S. and Ratcliffe N., Volatile Organic Compounds as Diagnostic Biomarkers in Gastrointestinal and Liver Diseases. J Gastrointestin Liver Dis., 18(3), pp. 337-343, 2009.

[7] Amico A., Di Natale C., Paolesse R., Macagnano A., Martinelli E., Pennazza G., Santonico M., Bernabei M., Roscioni C., Galluccio G., Bono R. and Finazzi Agrò E., Olfactory systems for medical applications. Sensor Actuat B, 130, pp. 458-465, 2008.

[8] Studer S., Orens J., Rosas I., Krishnan J., Cope K., Yang S., Conte J., Becker P. and Risby T., Patterns and significance of exhaled-breath biomarkers in lung transplant recipients with acute allograft rejection. J. Heart Lung Transplant., 20, pp. 1158-1166, 2001.

[9] Ciaffoni L., Peverall R. and Ritchie G., Laser spectroscopy on volatile sulfur compounds: possibilities for breath analysis, J. Breath Res., 5, 2011.

[10] Gajdocsy R. and Horvath I., Exhaled carbon monoxide in airway diseases: from research findings to clinical relevance, J. Breath Res., 4(4), pp. 7, 2010.

[11] Applegate, L., Luscher, P. and Tyrrell R., Induction of heme oxygenase: a general response to oxidant stress in cultured mammalian cells. Cancer Res., 51, pp. 974-978, 1991.

[12] Dweik R. Nitric oxide in exhaled breath: a window on lung physiology and pulmonary disease (Chapter 7). Topics in Breath Analysis for Clinical Diagnosis and Therapeutic Monitoring. Amann A. and Smith D. (eds). World Scientific: Singapore, pp. 121-139, 2005.

[13] MacGregor G., Ellis S., Andrews J., Imrie M., Innes A., Greening A., and Cunningham S., Breath condensate ammonium is lower in children with chronic asthma. Eur. Respir. J., 26, pp. 271-276, 2005.

[14] Davies S., Spanel P. and Smith D., Quantitative Analysis of Ammonia on the Breath of Patients in End-Stage Renal Failure. Kidney International, 52 (1), pp. 223-228, 1997. 
[15] Buszewski B., Kłodzińska E., Dahm H., Różycki H., Szeliga J. and Jackowski M., Rapid identification of Helicobacter pylori by capillary electrophoresis: an overview. Biomed. Chromatogr. 21:, pp. 116-122, 2007.

[16] Wojtas J., Bielecki Z., Stacewicz T., Mikolajczyk J. and Nowakowski M., Ultrasensitive laser spectroscopy for breath analysis. Opto-Electron. Rev. 20(1), pp.26-39, 2012.

[17] Oxley C., Explosive detection: potential problems. Proc. SPIE, 2511, pp. 217-225, 1995.

[18] Blue R., Vobecka Z., Skabara P. and Uttamchandani D., The development of sensors for volatile nitro-containing compounds as models for explosives detection. Sensors and Actuators B, 176, pp. 534-542, 2013.

[19] Teshima N., Li J., Toda K. and Dasgupta P., Determination of acetone in breath. Analytica Chemica Acta, 545, pp. 189-99, 2005.

[20] Caygill J., Davis F. and Higson S., Current trends in explosive detection techniques, Talanta, 88, pp. 14-29, 2012.

[21] US Patent 2009/0090196A1, Preconcentrator and Detector Apparatus, 2009.

[22] US Patent 8,127,595 B2, Pre-concentrator and sample interface, 2012.

[23] US Patent 2010/0307224A1, Preconcentrators and methods of making and using the same, 2010.

[24] Manginell R., Frye-Mason G., Kottenstette R., Lewis P. and Wong C., Microfabricated planar preconcentrator. Tech. Digest 2000 Sol.-State Sensor and Actuator Workshop Transducers Research Foundation, Cleveland, OH, USA, pp. 179-182, 2000.

[25] US Patent No. 0095722 A1, Microscale fabricated flow through sorbent plate collection device, 2005.

[26] Martin M., Crain M., Walsh K., McGill R., Houser E., Mott D., Stepnowski J., Stepnowski S., Nguyen V., Wu H.-D., Ross S., Nagel D. and Voiculescu I., Development of a Microfabricated Vapor Preconcentrator for Portable Ion Mobility Spectroscopy, Solid-State Sensor, Actuator and Microsystems Workshop, Hilton Head Island, SC, USA, pp. 390-391, 2004.

[27] Martin M., Crain M., Walsh K., McGill R., Houser E., Stepnowski J., Stepnowski S., Wu H.-D. and Ross S., Sens. Actuators B. 126(2) (2007) 447.

[28] U.S. Patent 6,660,230. Linear chemoselective carbosilane polymers and methods for use in analytical and purification applications, 2003.

[29] Gracia I., Ivanov P., Blanco F., Sabate N., Vilanova X., Correig X., Fonseca L., Figueras E., Santander J. and Cane C., Sub-ppm gas sensor detection via spiral $\mu$-preconcentrator. Sens. Actuators B., 132, pp. 149-154, 2008.

[30] Rydosz A., Maziarz W., Pisarkiewicz T., Domański K. and Grabiec P., A gas micropreconcentrator for low level acetone measurements. Microelectronics Reliability, 52, pp. 2640-2646, 2012.

[31] Ulanowska A., Kowalkowski T., Hrynkiewicz K., Jackowski M. and Buszewski B., Determination of volatile organic compounds in human 
breath for Helicobacter pylori detection by SPME-GC/MS. Biomedical Chromatography, 25(3), p.p. 391-397, 2011.

[32] Buszewski B., Ulanowska A., Ligor T., Jackowski M., Kłodzińska E. and Szeliga J. Identification of volatile organic compounds secreted from cancer tissues and bacterial cultures. J. of Chrom. B, 868, pp. 88-94. 2008.

[33] Song G., Qin T., Liu H., Xu G.-B., Pan Y.-Y., Xiong F.-X., Gu K.-S., Sun G.-P. and Chen Z.-D., Quantitative breath analysis of volatile organic compounds of lung cancer patients. Lung Cancer, 67(2), pp. 227-231, 2010.

[34] Lai H., Leung A., Magee M. and Almirall J., Identification of volatile chemical signatures from plastic explosives by SPME-GC/MS and detection by ion mobility spectrometry. Anal Bioanal Chem, 396, pp. $2997-$ 3007, 2010.

[35] Means Engineering Staff, RSMeans Illustrated Construction Dictionary Student ed., John Wiley and Sons, 2012.

[36] Freni A., Frazzica A., Dawoud B., Chmielewski S., Calabrese L. and Bonaccorsi L., Adsorbent coatings for heat pumping applications: Verification of hydrothermal and mechanical stabilities. Applied Thermal Engineering, 4, pp. 1-6, 2011.

[37] Mohsen Y., Sanchez J., Berger F., Lahlou H., Bezverkhyy I., Fierro V., Weber G., Celzard A. and Bellat J., Selection and characterization of adsorbents for the analysis of an explosives-related molecule traces in the air. Sensors and Actuators B, 176, pp. 124-131, 2013.

[38] Lahlou H., Vilanova X., Fierro V., Celzard A., Llobet E. and Correig X., Preparation and characterisation of a planar pre-concentrator for benzene based on different activated carbon materials deposited by air-brushing. Sensors and Actuators B, 154(2), pp. 213-219, 2011.

[39] Ramos M., Bonellia P., Cukierman A., Ribeiro Carrott M. and Carrott P., Adsorption of volatile organic compounds onto activated carbon cloths derived from a novel regenerated cellulosic precursor. J. Hazard. Mat., 177, pp. 175-182, 2010.

[40] Alfeeli B., Cho D., Ashraf-Khorassani M., Taylor L. and Agah M., MEMSbased multi-inlet/outlet preconcentrator coated by inkjet printing of polymer adsorbents. Sensors and Actuators B, 133, pp. 24-32, 2008.

[41] Camara E., Breuil P., Briand D., de Rooij N. and Pijolat C., A micro gas preconcentrator with improved performance for pollution monitoring and explosives detection. Analytica Chimica Acta, 688, pp. 175-182, 2011.

[42] Kruk M., Li Z., Jaroniec M. and Betz W., Nitrogen adsorption study of surface properties of graphitized carbon blacks. Langmuir, 15, pp. 14351441, 1998.

[43] Serrano G., Sukaew T. and Zellers E., Hybrid Preconcentrator/Focuser Module for Determinations of Explosive Marker Compounds with a MicroScale Gas Chromatograph. J. of Chrom. A, (Accepted Manuscript), 2013.

[44] Breck D. (1974) Zeolite Molecular Sieves, Structure, Chemistry and Use, John Wiley and Sons, Inc., New York; reprinted by Krieger, Florida, 1984. 
[45] Yang R., Gas separation by adsorption methods, Beijing, China: Publishing House of Chemical Industry (in Chinese), 1991.

[46] Bein T., Brown K., Frye G. and Brinker C., Molecular sieve sensors for selective detection at the nanogram level. J. Am. Chem. Soc., 111, pp. 7640-7641, 1989.

[47] Hugon O., Sauvan M., Benech P., Pijolat C. and Lefebvre F., Gas separation with a zeolite filter, application to the selectivity enhancement of chemical sensors. Sensors and Actuators B, 67, pp. 235-243, 2000.

[48] Saraoglu H. and Koçan M., Determination of Blood Glucose Level-Based Breath Analysis by a Quartz Crystal Microbalance Sensor Array. IEEE Sensors Journal, 10(1), 2010.

[49] Proquitté H., Rüdiger M., Wauer R. and Schmalisch G., Breathing gas perfluorocarbon measurements using an absorber filled with zeolites. $\mathrm{Br} . J$. Anaesth, 91(5), pp. 736-738, 2003

[50] Alfeeli B., Taylor L. and Agah M., Evaluation of Tenax TA thin films as adsorbent material for micro preconcentration applications. Microchem. J., 95(2), pp. 259-267, 2010.

[51] Alfeeli B. and Agah M., Toward Handheld Diagnostics of Cancer Biomarkers in Breath: Micro Preconcentration of Trace Levels of Volatiles in Human Breath. IEEE Sensors Journal, 11(11), 2011.

[52] Grate J. and Ewing R., Atkinson D., Vapor-generation methods for explosives-detection research. Trends in Analytical Chemistry, 41, 2012.

[53] Poole C. and Schuette S., Contemporary Practice of Chromatography, Elsevier, New York, pp. 39. 1984.

[54] Kannan G. and Kappor J., Adsorption studies of carbowax and poly dimethyl siloxane to use as chemical array for nitro aromatic vapour sensing. Sensors and Actuators: B. Chemical, 110(2), pp. 312-320, 2005.

[55] Rutecka B., Wojtas J., Bielecki Z., Mikolajczyk J. and Nowakowski M., Application of an optical parametric generator to cavity enhanced experiment. Proc. of SPIE, 7745, pp. 77450I-1. 2010.

[56] Wojtas J., Czyzewski A., Stacewicz T. and Bielecki Z., Sensitive detection of $\mathrm{NO}_{2}$ with Cavity Enhanced Spectroscopy. Opt. Appl. 36, pp. 461-467, 2006.

[57] Bielecki Z., Stacewicz T., Wojtas J., Nowakowski M. and Mikolajczyk J., Polish patent application No P.394439 (2011).

[58] Wojtas J., Mikolajczyk J., Nowakowski M., Rutecka B., Medrzycki R. and Bielecki Z., Appling CEAS method to UV,VIS, and IR spectroscopy sensors. Bull. Pol. Ac: Tech., 59, 2011.

[59] Stacewicz T., Wojtas J., Bielecki Z., Nowakowski M., Mikolajczyk J., Medrzycki R. and Rutecka B., Cavity Ring Down Spectroscopy: detection of trace amounts of matter. Opto-Electron. Rev., 20, pp.77-90, 2012.

[60] Wojtas J., Medrzycki R., Rutecka B., Mikolajczyk J., Nowakowski M., Szabra D., Gutowska M., Stacewicz T. and Bielecki Z., NO and $\mathrm{N}_{2} \mathrm{O}$ detection employing cavity enhanced technique, Proc. SPIE, 8374, pp. $837414,2012$. 
[61] Wojtas J., Stacewicz T., Bielecki Z., Rutecka B., Mędrzycki R., and Mikolajczyk J., Towards optoelectronic detection of explosives. OptoElectron. Rev., 21(2), 2013 (in printing).

[62] Pustelny T., Maciak E., Opilski Z. and Bednorz M., Optical interferometric structures for application in gas sensors. Opt. Appl., 37(102), pp. 187-194. 2007.

[63] Struk P., Pustelny T., Golaszewska K., Kaminska E., Borysewicz M., Ekielski M. and Piotrowska A., Photonic structures with grating couplers based on ZnO. Opto-Electron Rev., 19(4), pp. 462-467, 2011.

[64] Bielecki Z., Janucki J., Kawalec A., Mikołajczyk J., Pałka N., Pasternak M., Pustelny T., Stacewicz T. and Wojtas J., Sensors and systems for the detection of explosive devices -an overview. Metrol. Meas. Syst., XIX (1), pp. 3-28, 2012.

[65] Wojtas J., Bielecki Z., Cudziło S., Nowakowski M., Rutecka B., Niedbała R. and Wesołowski M., Projekt układu zatężania i dekompozycji par materiałów wybuchowych. Przeg. Elektrotech. 11a, pp. 225-228, 2010 (in Polish). 